\title{
Antiadhesive activity of the biosurfactant pseudofactin II secreted by the Arctic bacterium Pseudomonas fluorescens BD5
}

\author{
Tomasz Janek', Marcin Łukaszewicz ${ }^{1,2}$ and Anna Krasowska ${ }^{1,2^{*}}$
}

\begin{abstract}
Background: Pseudofactin II is a recently identified biosurfactant secreted by Pseudomonas fluorescens BD5, the strain obtained from freshwater from the Arctic Archipelago of Svalbard. Pseudofactin II is a novel compound identified as cyclic lipopeptide with a palmitic acid connected to the terminal amino group of eighth amino acid in peptide moiety. The C-terminal carboxylic group of the last amino acid forms a lactone with the hydroxyl of Thr3.

Adhesion is the first stage of biofilm formation and the best moment for the action of antiadhesive and antibiofilm compounds. Adsorption of biosurfactants to a surface e.g. glass, polystyrene, silicone modifies its hydrophobicity, interfering with the microbial adhesion and desorption processes. In this study the role and applications of pseudofactin II as a antiadhesive compound has been investigated from medicinal and therapeutic perspectives.

Results: Pseudofactin II lowered the adhesion to three types of surfaces (glass, polystyrene and silicone) of bacterial strains of five species: Escherichia coli, Enterococcus faecalis, Enterococcus hirae, Staphylococcus epidermidis, Proteus mirabilis and two Candida albicans strains. Pretreatment of a polystyrene surface with $0.5 \mathrm{mg} / \mathrm{ml}$ pseudofactin II inhibited bacterial adhesion by $36-90 \%$ and that of C. albicans by $92-99 \%$. The same concentration of pseudofactin II dislodged 26-70\% of preexisting biofilms grown on previously untreated surfaces. Pseudofactin II also caused a marked inhibition of the initial adhesion of E. faecalis, E. coli, E. hirae and C. albicans strains to silicone urethral catheters. The highest concentration tested $(0.5 \mathrm{mg} / \mathrm{ml})$ caused a total growth inhibition of $\mathrm{S}$. epidermidis, partial (18-37\%) inhibition of other bacteria and 8-9\% inhibition of C. albicans growth.

Conclusion: Pseudofactin II showed antiadhesive activity against several pathogenic microorganisms which are potential biofilm formers on catheters, implants and internal prostheses. Up to 99\% prevention could be achieved by $0.5 \mathrm{mg} / \mathrm{ml}$ pseudofactin II. In addition, pseudofactin II dispersed preformed biofilms. Pseudofactin II can be used as a disinfectant or surface coating agent against microbial colonization of different surfaces, e.g. implants or urethral catheters.
\end{abstract}

Keywords: Biosurfactant, Lipopeptide, Adhesion, Biofilm, Uropathogenic microorganisms

\section{Background}

Biofilms, which are formed by the majority of microorganisms in natural environments, are structures with low sensitivity to drugs [1]. Many laboratories are synthesizing or isolating new compounds preventing the formation of biofilms or causing their elimination $[2,3]$.

\footnotetext{
* Correspondence: aniak@biotrans.uni.wroc.pl

'Faculty of Biotechnology, University of Wroclaw, Przybyszewskiego 63/77, Wroclaw 51-148, Poland

Full list of author information is available at the end of the article
}

Adhesion is the first stage of biofilm formation and the best moment for the action of antiadhesive and anti-biofilm compounds. Biosurfactants are promising compounds often showing antimicrobial and antiadhesive properties and sometimes penetrating and removing mature biofilms [4]. Microbial surfactants-amphiphilic, surface-active, secondary metabolites of bacteria or fungi ranging from low-molecular-mass glycolipids, sophorolipids, rhamnolipids and lipopeptides, to high-molecularmass proteins, lipopolysaccharides and lipoproteins [5]-
C Biomed Central

(C) 2011 Janek et al; licensee BioMed Central Ltd. This is an Open Access article distributed under the terms of the Creative Commons Attribution License (http://creativecommons.org/licenses/by/2.0), which permits unrestricted use, distribution, and reproduction in any medium, provided the original work is properly cited. 
can interact with interfaces and inhibit the adhesion of microorganisms to different surfaces. They are an alternative to synthetic surface-active agents because of their low toxicity and biodegradability [6].

Another mechanism of biosurfactant action is the permeabilization of bacterial cells. The rhamnolipid secreted by Pseudomonas sp. S-17 permeabilized Gramnegative and Gram-positive cells, but a strong inhibition of growth was observed only in the case of Gram-positive bacteria [7]. Biofilm disruption was observed after the addition of rhamnolipids from Pseudomonas aeruginosa [8] and lipopeptide from Bacillus spp. [9]. A particular group of biosurfactants, lipopeptides, can act as antibiotics and also as antiviral [10] and antitumor agents [11]. Surfactin from Bacillus subtilis can interact with the plasma membranes of bacterial and fungal cells leading to their disruption [12]. The effects of biosurfactants on decreased microbial adhesion and detachment from different surfaces can be conveniently utilized in many fields, from medicine to various branches of industry, e.g., antimicrobial or antitumor activities $[13,14]$ and their surface activity and antiadhesive properties can be suitable for preventing microbial colonization of implants or urethral catheters. Microbial surfactants from Lactobacillus fermentum and Lactobacillus acidophilus adsorbed on glass, reduced the number of adhering uropathogenic cells of Enterococcus faecalis by $77 \%$ [15]. A surfactant released by Streptococcus thermophilus has been used for fouling control of heat-exchanger plates in pasteurizers as it retards the colonization of other thermophilic strains of Streptococcus responsible for fouling [16].

Within the collection of 132 morphologically distinct bacteria isolated from water and ground provided from the wild environment around the University of Wroclaw scientific base in the Arctic Archipelago of Svalbard [17], Pseudomonas fluorescens BD5 was identified as strain which strongly reduces surface tension of its culture supernatant [18]. We purified and identified the chemical structure of two new P. fluorescens BD5 biosurfactants, pseudofactin I and II [19]. Both compounds are cyclic lipopeptides with a palmitic acid connected to the terminal amino group of an octapeptide. The $\mathrm{C}$ terminal carboxylic group of the last amino acid (Val or Leu) forms a lactone with the hydroxyl of Thr3. The biosurfactant was found to be stable within the range from $-20^{\circ} \mathrm{C}$ to $100^{\circ} \mathrm{C}$, had the minimum surface tension $(31.5 \mathrm{mN} / \mathrm{m})$ and the critical micelle concentration $(72$ $\mathrm{mg} / \mathrm{L})$ [19]. Emulsification activity and stability of pseudofactin II was greater than that of the synthetic surfactants such as Tween 20 and Triton X-100.

The aim of this paper was to assess how the pseudofactin II influences the adhesion and biofilm formation of microorganisms such as Escherichia coli, E. faecalis,
Enterococcus hirae, Staphylococcus epidermidis, Proteus mirabilis, Vibrio ordali, Vibrio harveyi and Candida albicans found in gastrointestinal and urinary tract. Since the effects of a surfactant may differ depending on both the type of the microorganism and the type of surface it adheres to, we tested its action on the adherence of the above pathogenic microorganisms to three types of surfaces, polystyrene, glass (as standard laboratory surfaces for adhesion tests) and silicone (used in medical application such as urethral catheters).

\section{Methods}

\section{Microorganisms and culture conditions}

P. fluorescens BD5 strain was obtained from freshwater from the Arctic Archipelago of Svalbard [19] and maintained on the mineral salts medium MSM (7 g/L $\mathrm{K}_{2} \mathrm{HPO}_{4}, 2 \mathrm{~g} / \mathrm{L} \mathrm{KH} \mathrm{PO}_{4}, 1 \mathrm{~g} / \mathrm{L}\left(\mathrm{NH}_{4}\right)_{2} \mathrm{SO}_{4}, 0.5 \mathrm{~g} / \mathrm{L}$ sodium citrate $2 \mathrm{H}_{2} \mathrm{O}$, and $0.1 \mathrm{~g} / \mathrm{L} \mathrm{MgSO}_{4} .7 \mathrm{H}_{2} \mathrm{O}$ ) with $2 \%$ D-glucose.

The antimicrobial and antiadhesive properties of pseudofactin II were tested on several pathogenic strains that colonize animals gastrointestinal tract or medical devices. E. coli ATCC 25922, E. coli ATCC 10536, E. coli 17-2 (clinical isolate, Wroclaw Medical University), E. faecalis ATCC 29212, E. faecalis JA/3 (clinical isolate, Wroclaw Medical University), E. hirae ATCC 10541, S. epidermidis KCTC 1917 [20], P. mirabilis ATCC 21100 were grown at $37^{\circ} \mathrm{C}$ and $V$. harveyi ATCC 14126, V. ordalii $\mathrm{KCCM} 41669$ were grown at $28^{\circ} \mathrm{C}$ in $\mathrm{LB}$ medium (10 g/L bacto-tryptone, $5 \mathrm{~g} / \mathrm{L}$ bacto-yeast extract, $10 \mathrm{~g} / \mathrm{L}$ $\mathrm{NaCl}$ ). Two fungal strains, C. albicans ATCC 20231 and C. albicans SC5314 [21], were grown in a $6.7 \mathrm{~g} / \mathrm{L}$ yeast nitrogen base (YNB, pH 5.5), broth (Difco Laboratories) containing $2 \% \mathrm{D}$-glucose for adhesion tests. To prevent filamentation of C. albicans, pre-culture was incubated at $28^{\circ} \mathrm{C}$, while experiments with biofilms were performed at $37^{\circ} \mathrm{C}$. RPMI-1640 medium (Cambrex, Verviers, Belgium) was used for Candida biofilms formation.

\section{Isolation and purification of pseudofactin II}

Pseudofactin II produced by P. fluorescens BD5 was obtained by extraction of cell free supernatant by ethyl acetate and evaporation of the extract under vacuum. The crude biosurfactant was separated by RP-HPLC in the same manner as reported earlier [19]. Purified pseudofactin II fraction was dried and stored at $-20^{\circ} \mathrm{C}$ for further studies. Analytical RP-HPLC (data not shown) of purified pseudofactin II showed that its purity was > $99 \%$.

\section{Antimicrobial assays}

The antimicrobial activity of isolated pseudofactin II was determined by the microdilution method in 96-well flat- 
bottomed plastic microplates (Sarstedt, Nümbrecht, Germany). Briefly, $50 \mu \mathrm{l}$ volumes of sterile double strength LB (for bacterial) or YNB (for yeast) medium were dispensed into the wells of a 96-well microplate. Subsequently, $50 \mu \mathrm{l}$ volumes of pseudofactin II (0.035 to 0.5 $\mathrm{mg} / \mathrm{ml}$ ) solution in phosphate-buffered saline (PBS) were added to the microplate wells and mixed with the medium. Negative and growth control wells did not contain biosurfactant. All wells (except for negative controls) were inoculated with $2 \mu$ of overnight bacterial or yeast cultures (diluted to $\mathrm{OD}_{600}=0.1$ ) in $\mathrm{LB}$ or $\mathrm{YNB}$ medium respectively, and the microplates were incubated for $24 \mathrm{~h}$ at $37^{\circ} \mathrm{C}$ or $28^{\circ} \mathrm{C}$ for bacterial or yeast cultures, respectively. After $24 \mathrm{~h}$ of incubation, the optical density at $600 \mathrm{~nm}$ of each well was measured using an Asys UVM 340 (Biogenet) microplate reader. The growth inhibition percentages at different pseudofactin II concentrations for each microorganism were calculated as:

$$
\% \text { growth inhibition }=\left[1-\left(\frac{\mathrm{OD}_{\mathrm{T}}}{\mathrm{OD}_{\mathrm{C}}}\right)\right] \times 100
$$

where $\mathrm{OD}_{\mathrm{T}}$ represents the optical density of the well with a given pseudofactin II concentration and $\mathrm{OD}_{\mathrm{C}}$ is the optical density of the control well (growth without pseudofactin II). Assays were carried out three times in three replicates.

\section{Preadhesion treatment with pseudofactin II}

Inhibition of microbial adhesion by pseudofactin II was tested in 96-well plates (Sarstedt, Nümbrecht, Germany). Briefly, the wells of a sterile 96-well flat-bottom plate were filled with $100 \mu \mathrm{l}$ of $0.035-0.5 \mathrm{mg} / \mathrm{ml}$ pseudofactin II dissolved in PBS. The plates were incubated for $2 \mathrm{~h}$ at $37^{\circ} \mathrm{C}$ on a rotary shaker (MixMate, Eppendorf, Hamburg, Germany) at $300 \mathrm{rpm}$ and subsequently washed twice with PBS. Negative control (blank) wells contained pseudofactin II at the highest concentration tested $(0.5$ $\mathrm{mg} / \mathrm{ml}$ ) while positive control wells contained PBS buffer only. The overnight cultures of microbial strains were centrifuged, washed twice with PBS ( $\mathrm{pH}=7.4)$ and re-suspended in PBS to an optical density $\mathrm{OD}_{600}=1.0$ for bacterial and $\mathrm{OD}_{600}=0.6$ for Candida strains. The highest adhesion without pseudofactin II were observed at these optical densities (data not shown). A $100 \mu \mathrm{l}$ aliquot of a washed microbial suspension was added and incubated in the wells. After a $2 \mathrm{~h}$ incubation at $37^{\circ} \mathrm{C}$ in a rotary shaker (MixMate, Eppendorf, Hamburg, Germany) at $300 \mathrm{rpm}$ nonadherent cells were removed by three washes with PBS. Then the plates were stained with $0.1 \%$ crystal-violet for $5 \mathrm{~min}$ and again washed three times with PBS. The adherent microorganisms were permeabilized and the dye was resolubilized with
$150 \mu \mathrm{l}$ of isopropanol-0.04 $\mathrm{N} \mathrm{HCl}$ and $50 \mu \mathrm{l}$ of $0.25 \%$ SDS per well. Crystal violet optical density readings of each well were taken at $590 \mathrm{~nm}$ on the Asys UVM 340 (Biogenet) microplate. Pseudofactin II did not affect the absorption of negative control (crystal violet in blank wells). The microbial adhesion inhibition was calculated as growth inhibition. Assays were carried out three times in three replicates.

\section{Postadhesion treatment with pseudofactin II}

The 96-well flat-bottomed plates were incubated for $2 \mathrm{~h}$ on a rotary shaker (MixMate, Eppendorf, Hamburg, Germany) at $300 \mathrm{rpm}$ with $100 \mu \mathrm{l}$ of bacterial suspension $\left(\mathrm{OD}_{600}=1.0\right)$ and Candida suspension $\left(\mathrm{OD}_{600}=\right.$ $0.6)$ in $\mathrm{PBS}$ at $37^{\circ} \mathrm{C}$. Unattached microbial cells were removed by washing the wells three times with PBS. Next, $100 \mu \mathrm{l}$ of $0.035-0.5 \mathrm{mg} / \mathrm{ml}$ pseudofactin II was added to each well and incubated at $37^{\circ} \mathrm{C}$ for $2 \mathrm{~h}$ on a rotary shaker (MixMate, Eppendorf, Hamburg, Germany) at $300 \mathrm{rpm}$. Control wells contained only PBS. The plates were washed three times, adherent cells were fixed with $100 \mu \mathrm{l}$ of $0.1 \%$ crystal violet for $5 \mathrm{~min}$ and again washed three times with PBS. The adherent microorganisms were permeabilized and the dye was resolubilized with $150 \mu \mathrm{l}$ of isopropanol-0.04 N HCl and $50 \mu \mathrm{l}$ of $0.25 \%$ SDS per well. The crystal violet optical density of each well was measured at $590 \mathrm{~nm}$ using the microplate reader. Assays were carried out three times in three replicates. The microbial adhesion dislodging percentages at different pseudofactin II concentrations for each microorganism were calculated as:

$$
\% \text { growth inhibition }=\left[1-\left(\frac{\mathrm{OD}_{\mathrm{T}}}{\mathrm{OD}_{\mathrm{C}}}\right)\right] \times 100
$$

where $\mathrm{OD}_{\mathrm{T}}$ represents the optical density of the well with a given pseudofactin II concentration and $\mathrm{OD}_{\mathrm{C}}$ the optical density of the control well (without pseudofactin II). Assays were carried out three times in three replicates.

\section{Confocal laser scanning microscopy}

Confocal laser scanning microscopy (CLSM) was used for visualizing the formation of bacterial and Candida biofilms in the absence or presence of pseudofactin II (final concentration $0.25 \mathrm{mg} / \mathrm{ml}$ ) in the culture medium. Bacterial and yeast biofilms were formed on Thermanox plastic coverslips (Nalgen Nunc International Co., Rochester, NY), glass microscopic coverslips (MenzelGlaser, Germany) and segments of silicone urethral catheters (Unomedical, Denmark) placed in wells of 24well plates (Nalgen Nunc International Co., Rochester, NY) containing LB medium for bacteria and RPMI-1640 medium for yeast. Inocula were prepared as follows: 24 
$\mathrm{h}$ old overnight cultures were harvested and re-suspended at normalized dilutions $\left(\mathrm{OD}_{600}=0.01\right)$. Five hundred microliters inocula were injected into the wells with the coverslips and incubated for $24 \mathrm{~h}$ at $37^{\circ} \mathrm{C}$. After this time, the coverslips were washed with PBS for $15 \mathrm{~min}$. Then, the bacterial biofilms were stained for 30 min at $37^{\circ} \mathrm{C}$ with $1 \mathrm{ml}$ of $0.6 \%$ Live/Dead BacLight viability stain (Molecular Probes, Eugene, OR) dissolved in PBS, and PBS-containing concanavalin A-Alexa Fluor 488 (Molecular Probes, Eugene, OR) conjugate (0.025 $\mathrm{mg} / \mathrm{ml}$ ) for Candida biofilms. The stained biofilms were visualized by CLSM with an Olympus FluoView 500 (Olympus Optical Co. Ltd., Japan) microscope. The CLSM used an argon ion laser at 480-490 nm for excitation and a 500-635 $\mathrm{nm}$ band pass filter for emission. CLSM images were processed by Olympus FluoView 500 software. Assays were carried out two times. Representative images are presented on Figure 1.

\section{Biofilm formation in urethral catheters}

The uropathogenic strains E. coli, E. faecalis, E. hirae and $C$. albicans were used in these tests. Ten microliter volumes of overnight cultures of E. coli ATCC 25922, E. faecalis ATCC 29212, E. hirae ATCC 10541 were added into $1000 \mu \mathrm{l}$ of fresh LB medium, and the same volume of C. albicans SC5314 was added into $1000 \mu \mathrm{l}$ of fresh RPMI-1640 medium. To the medium was added $1000 \mu \mathrm{l}$ pseudofactin II (final concentration $0.25 \mathrm{mg} / \mathrm{ml}$ ) solution in LB medium (for bacterial) and RPMI-1640 medium for C. albicans and $4 \mathrm{~cm}$ long segments of sterile silicone urethral catheters (Unomedical, Denmark). The catheters were incubated at $37^{\circ} \mathrm{C}$ overnight. The cultures were removed and the catheters were washed with distilled water. After washing, $3000 \mu \mathrm{l}$ of crystal violet $(0.1 \%)$ was added to the catheters for $20 \mathrm{~min}$. The stained biofilms were rinsed three times with distilled water and allowed to dry at room temperature for 15 min before examination. In a parallel experiment the catheters were pretreated with pseudofactin II by being placed in a tube with $2000 \mu \mathrm{l}$ of $0.25 \mathrm{mg} / \mathrm{ml}$ pseudofactin II dissolved in PBS, incubated for $2 \mathrm{~h}$ at $37^{\circ} \mathrm{C}$ and subsequently washed twice with $\mathrm{PBS}$. Then the experiment was carried out as in the case of adding pseudofactin II into the growth medium. Assays were carried out two times. Representative images are presented on Figure 2. This experiment was carried out under dynamic conditions using a peristaltic pump, where the flow of culture with or without pseudofactin II trough urethral catheters was $50 \mathrm{ml} / \mathrm{h}$.

\section{Results and discussion}

\section{Antimicrobial activity of pseudofactin II}

Lipopeptides have typical amphiphilic structure of a surfactant, where the hydrophobic moiety is a hydroxyl or $\alpha$-alkyl- $\beta$-hydroxy fatty acid (e.g. $3-\mathrm{OH}-\mathrm{C}_{14}, 3-\mathrm{OH}-\mathrm{C}_{15}$ and $3-\mathrm{OH}-\mathrm{C}_{10}$ fatty acids) and the hydrophilic moiety is a short chain or a cyclic peptide [22,23]. Instead, the hydrophobic moiety of pseudofactin II contains palmitic acid, which is a saturated fatty acid having no hydroxyl group. Rhodofactin, another lipopeptide with palmitic acid, has been described by Peng et al. [24]; however, contrary to pseudofactin II it has a short peptide chain which does not form lactone ring. Its antimicrobial activity has not yet been described.

The antimicrobial activity of pseudofactin II isolated from $P$. fluorescens BD5 was evaluated at concentrations from 0.035 to $0.5 \mathrm{mg} / \mathrm{ml}$ (Table 1). At $0.5 \mathrm{mg} / \mathrm{ml}$ the agent caused a total growth inhibition of $S$. epidermidis KCTC 1917 and considerable growth inhibition of $P$. mirabilis ATCC 21100 (37\%), E. coli ATCC 10536 and E. coli 17-2 (32\%), E. hirae ATCC 10541 (28\%).

In contrast to surfactin or iturin, produced by $B$. subtilis [25,26], lichenysin from Bacillus licheniformis [27] or polymyxin B and E from Bacillus polymyxa [28], pseudofactin II showed much weaker dose dependent antimicrobial activity against most strains tested in this work (Table 1). Only for two Vibrio strains pseudofactin II completely inhibited the growth in the lowest tested concentration, thus they were not used in further experiments (data not shown). This may be due to its unique chemical structure different from any currently known lipopeptides, which features a hydrophobic alkyl chain without a hydroxyl moiety attached to cyclic peptide.

\section{Antiadhesive and cell-dislodging activity of pseudofactin II on polystyrene surfaces}

Adhesion of pathogenic microorganisms to solid surfaces or to infection sites has been found to be inhibited by biosurfactants capable of modifying the physico-chemical properties of the surface to reduce adhesion and biofilm formation on a given biomaterial.

Pseudofactin II was found to possess antiadhesive activity against all tested microorganisms. The pretreatment of polystyrene surfaces with pseudofactin II significantly decreased the adhesion of all bacteria and yeast, and this antiadhesive effect was concentration-dependent (Table 2). The highest reduction of adhesion (8099\%) was observed for C. albicans SC 5314, C. albicans ATCC 20231, P. mirabilis ATCC 21100 and E. coli ATCC 10536. The dislodging effect of pseudofactin II on preformed biofilms on untreated surfaces was lower than the preventive effect of pretreatment and was in the range of $26-70 \%$ for $0.5 \mathrm{mg} / \mathrm{ml}$ pseudofactin II (Table 3).

The adhesion of pathogenic bacteria to polystyrene surfaces was inhibited by two lipopeptide biosurfactants produced by B. subtilis and B. licheniformis [9], and 

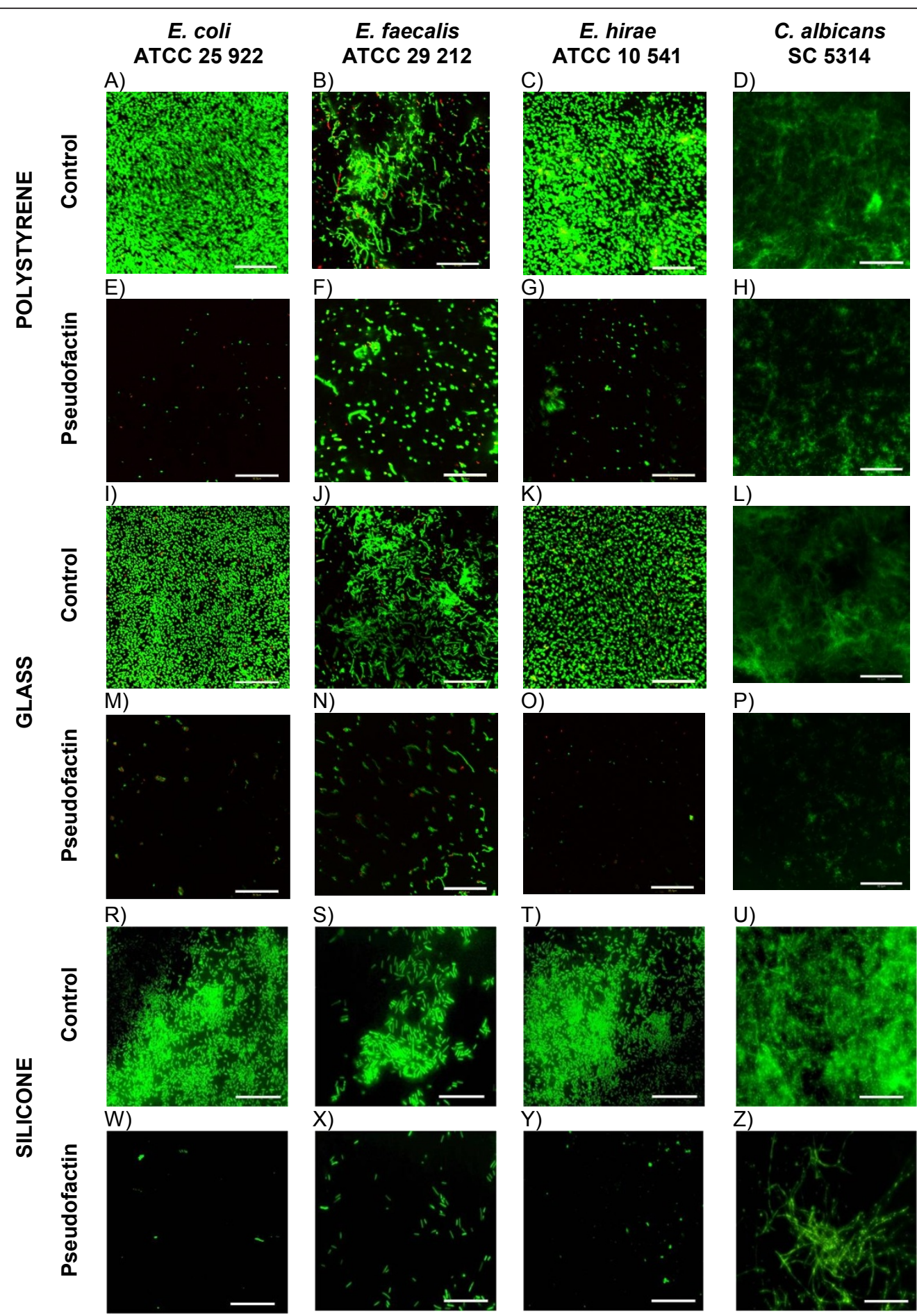

T)
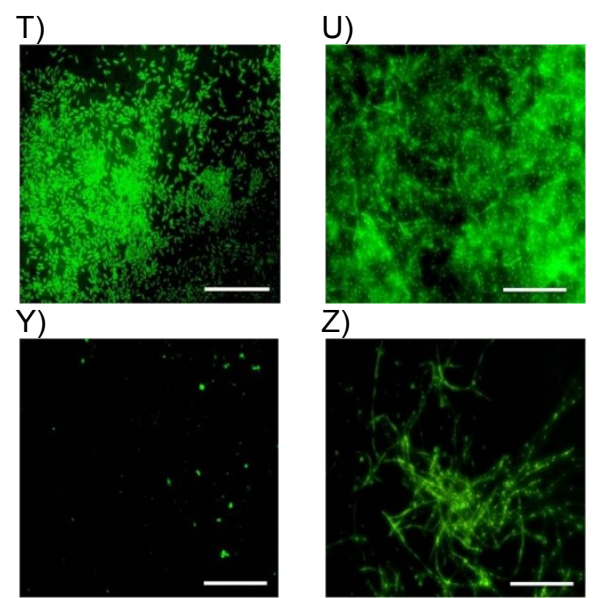

Figure 1 Confocal scanning laser microscopy images of biofilm formation on polystyrene, glass microscopic coverslips and cut fragment of silicone urethral catheters by different bacterial strains: ((A, I, R) Escherichia coli ATCC 25922, (B, J, S) Enterococcus faecalis ATCC 29212, (C, K, T) Enterococcus hirae ATCC 10541, (D, L, U) Candida albicans SC5314) and biofilm inhibition after incubation with pseudofactin II $(0.25 \mathrm{mg} / \mathrm{ml})$ in the culture medium: $(\mathrm{E}, \mathrm{M}, \mathrm{W})$ Escherichia coli ATCC $25922,(\mathrm{~F}, \mathrm{~N}, \mathrm{X})$ Enterococcus faecalis ATCC 29212, (G, O, Y) Enterococcus hirae ATCC 10541, (H, P, Z) Candida albicans muSC5314). Scale bars: $50 \mu \mathrm{l}$. 
A

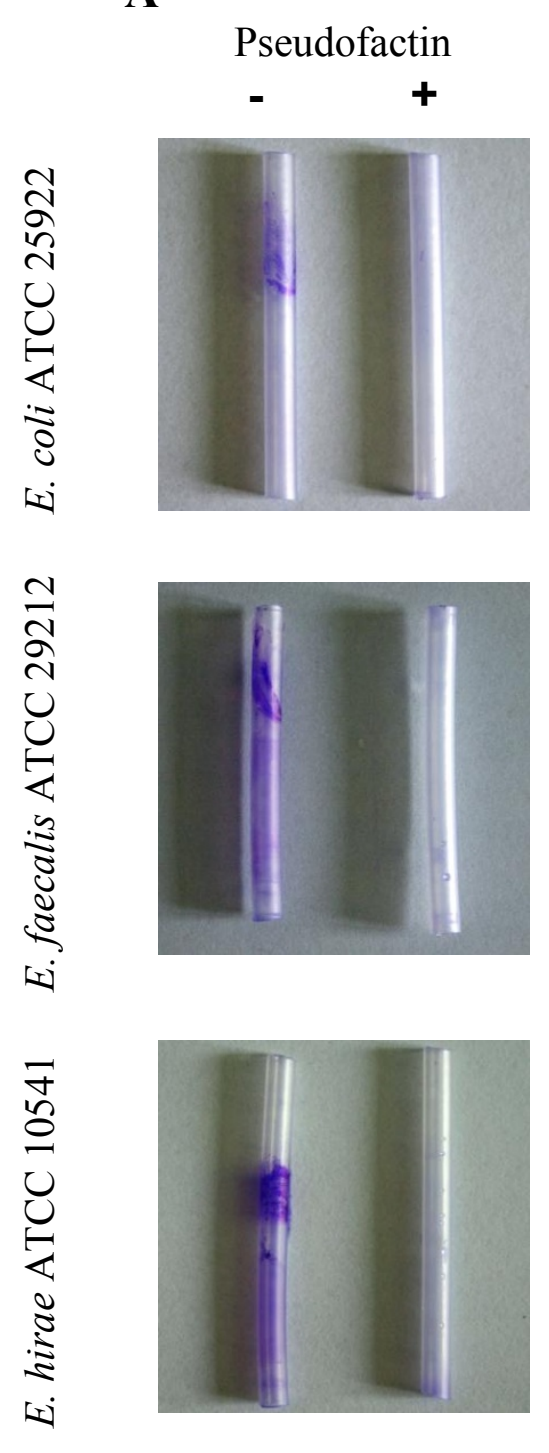

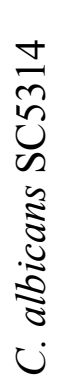

B
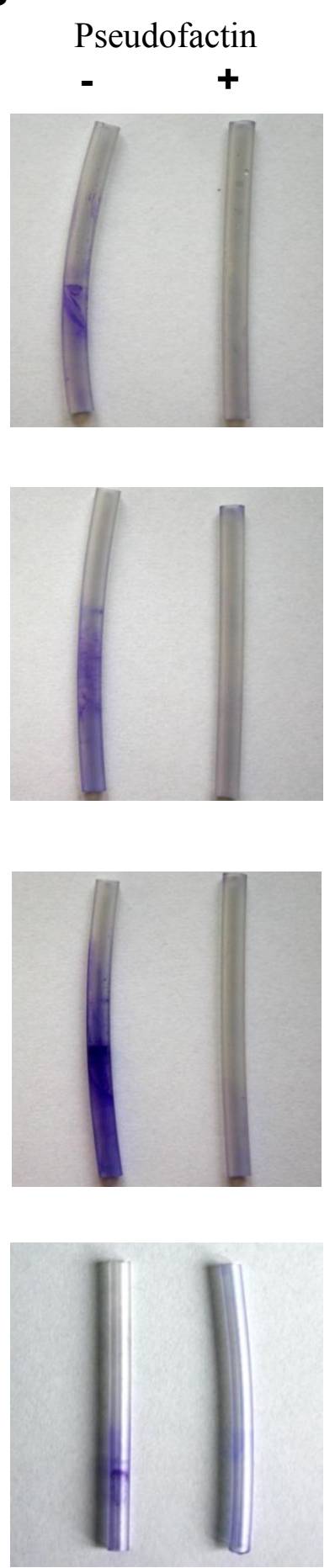

Figure 2 Pseudofactin II inhibits biofilm formation on silicone urethral catheters. The organisms were grown overnight at $37^{\circ} \mathrm{C}$ in a testtube with sterile urethral catheters containing medium (A) with and without $0.25 \mathrm{mg} / \mathrm{ml}$ pseudofactin II and (B) where the urethral catheters was pre-incubated with biosurfactant at concentration $0.25 \mathrm{mg} / \mathrm{ml}$ as described in the text. Biofilms were visualized by staining with crystal violet. 
Table 1 Growth inhibition obtained with the pseudofactin II isolated from P.fluorescens BD5 at different concentrations $(\mathrm{mg} / \mathrm{ml})$. Values \pm confidence interval, $\mathbf{n}=\mathbf{9}$

\begin{tabular}{|c|c|c|c|c|c|c|}
\hline \multirow[t]{3}{*}{ Microorganism } & \multicolumn{6}{|c|}{ Growth inhibition (\%) } \\
\hline & \multicolumn{6}{|c|}{ Pseudofactin II concentration (mg/ml) } \\
\hline & 0.500 & 0.250 & 0.200 & 0.150 & 0.075 & 0.035 \\
\hline Escherichia coli ATCC 25922 & $8 \pm 0.26$ & $7 \pm 0.52$ & $6 \pm 0.26$ & $5 \pm 0.39$ & $3 \pm 0.20$ & $0 \pm 0.26$ \\
\hline Escherichia coli ATCC 10536 & $32 \pm 0.26$ & $28 \pm 0.26$ & $27 \pm 0.39$ & $18 \pm 0.46$ & $2 \pm 0.26$ & $2 \pm 0.39$ \\
\hline Escherichia coli 17-2 & $32 \pm 0.46$ & $29 \pm 0.33$ & $24 \pm 0.20$ & $19 \pm 0.20$ & $14 \pm 0.20$ & $6 \pm 0.20$ \\
\hline Enterococcus faecalis ATCC 29212 & $18 \pm 0.07$ & $13 \pm 0.07$ & $11 \pm 0.07$ & $5 \pm 0.13$ & $5 \pm 0.13$ & $2 \pm 0.07$ \\
\hline Enterococcus faecalis JA/3 & $18 \pm 0.07$ & $15 \pm 0.07$ & $8 \pm 0.07$ & $4 \pm 0.07$ & $3 \pm 0.07$ & $0 \pm 0.07$ \\
\hline Enterococcus hirae ATCC 10541 & $28 \pm 0.26$ & $25 \pm 0.33$ & $22 \pm 0.13$ & $21 \pm 0.46$ & $10 \pm 0.13$ & $5 \pm 0.52$ \\
\hline Staphylococcus epidermidis KCTC 1917 & $100 \pm 0.07$ & $49 \pm 0.07$ & $44 \pm 0.39$ & $42 \pm 0.20$ & $16 \pm 0.33$ & $4 \pm 0.26$ \\
\hline Proteus mirabilis ATCC 21100 & $37 \pm 0.33$ & $36 \pm 0.20$ & $20 \pm 0.20$ & $17 \pm 0.39$ & $13 \pm 0.13$ & $0 \pm 0.39$ \\
\hline Candida albicans ATCC 20231 & $18 \pm 0.26$ & $17 \pm 0.39$ & $15 \pm 0.46$ & $15 \pm 0.13$ & $14 \pm 0.26$ & $11 \pm 0.20$ \\
\hline Candida albicans SC5314 & $9 \pm 0.07$ & $7 \pm 0.07$ & $5 \pm 0.20$ & $4 \pm 0.213$ & $1 \pm 0.07$ & $0 \pm 0.07$ \\
\hline
\end{tabular}

adhesion of Listeria monocytogenes to polystyrene microplates was reduced by $84 \%$ on pretreating the surface with surfactin $(1 \mathrm{mg} / \mathrm{ml})$, and by $82 \%$ when it was treated with purified rhamnolipid $(7.5 \mathrm{mg} / \mathrm{ml})$ [29]. Gudina et al. [30] characterized the anti-adhesive activity of biosurfactants against several microorganisms including Gram-positive and Gram-negative bacteria. This biosurfactant at concentration $25 \mathrm{mg} / \mathrm{ml}$ showed high anti-adhesive activity against Staphylococcus aureus (72.0\%), S. epidermidis (62.1\%), Streptococcus agalactiae (60.0\%) and low anti-adhesive activity against $P$. aeruginosa $(16.5 \%)$ and E. coli (11.5\%).

Coating with pseudofactin II was effective above critical micelle concentration $(0.072 \mathrm{mg} / \mathrm{ml})$ [19]. Our results suggest that when the surface is covered by pseudofactin II micelles attached to polystyrene by van der Waals forces, the adhesion is inhibited more strongly than it is with monomers.
Pseudofactin II reduces biofilm formation on polystyrene, glass and silicone

Biofilms are defined as microorganisms attached to a diverse range of biotic and abiotic surfaces and proliferating on them. The human body and medical devices or implants including: urinary catheters, voice prostheses, orthopedic implants, ocular prostheses and contact lenses are exposed to adhesion and biofilm formation by many opportunistic microorganisms. Thus we have tested the influence of pseudofactin II on biofilm formation on different materials.

The activity of pseudofactin II against biofilm formation was visualized by confocal laser scanning microscopy (Figure 1). The biofilm growth of E. coli, $E$. faecalis, E. hirae and C. albicans on polystyrene, glass and silicone from urethral catheters is shown in Figures $1 \mathrm{~A}-\mathrm{D}, 1 \mathrm{I}-\mathrm{L}$ and $1 \mathrm{R}-\mathrm{U}$, respectively. The biosurfactant inhibited biofilm formation at the concentration 0.25

Table 2 Microbial adhesion inhibition in the microtiter plate by purified pseudofactin II.

\begin{tabular}{|c|c|c|c|c|c|c|c|c|}
\hline \multirow[t]{3}{*}{ Microorganism } & \multicolumn{8}{|c|}{ Microbial adhesion inhibition (\%) } \\
\hline & \multicolumn{7}{|c|}{ Pseudofactin II concentration (mg/ml) } & \multirow{2}{*}{$\begin{array}{c}\text { Control (PBS) } \\
0\end{array}$} \\
\hline & 0.500 & 0.35 & 0.250 & 0.200 & 0.150 & 0.075 & 0.035 & \\
\hline Escherichia coli ATCC 25922 & $66 \pm 0.13$ & $65 \pm 0.13$ & $65 \pm 0.07$ & $64 \pm 0.07$ & $62 \pm 0.07$ & $58 \pm 0.07$ & $55 \pm 0.20$ & 0 \\
\hline Escherichia coli ATCC 10536 & $80 \pm 0.13$ & $80 \pm 0.13$ & $80 \pm 0.13$ & $77 \pm 0.13$ & $72 \pm 0.13$ & $65 \pm 0.07$ & $39 \pm 0.13$ & 0 \\
\hline Escherichia coli 17-2 & $72 \pm 0.33$ & $71 \pm 0.13$ & $71 \pm 0.13$ & $69 \pm 0.13$ & $68 \pm 0.07$ & $64 \pm 0.07$ & $64 \pm 0.13$ & 0 \\
\hline Enterococcus faecalis ATCC 29212 & $70 \pm 0.20$ & $68 \pm 0.20$ & $68 \pm 0.13$ & $57 \pm 0.13$ & $55 \pm 0.07$ & $54 \pm 0.07$ & $42 \pm 0.13$ & 0 \\
\hline Enterococcus faecalis JA/3 & $36 \pm 0.13$ & $36 \pm 0.13$ & $34 \pm 0.13$ & $31 \pm 0.13$ & $22 \pm 0.13$ & $18 \pm 0.20$ & $15 \pm 0.07$ & 0 \\
\hline Enterococcus hirae ATCC 10541 & $71 \pm 0.07$ & $71 \pm 0.20$ & $71 \pm 0.20$ & $67 \pm 0.20$ & $66 \pm 0.13$ & $61 \pm 0.07$ & $58 \pm 0.13$ & 0 \\
\hline Staphylococcus epidermidis KCTC 1917 & $55 \pm 0.13$ & $45 \pm 0.07$ & $45 \pm 0.07$ & $33 \pm 0.13$ & $32 \pm 0.07$ & $31 \pm 0.13$ & $29 \pm 0.13$ & 0 \\
\hline Proteus mirabilis ATCC 21100 & $90 \pm 0.20$ & $90 \pm 0.33$ & $90 \pm 0.33$ & $89 \pm 0.13$ & $87 \pm 0.07$ & $85 \pm 0.20$ & $84 \pm 0.20$ & 0 \\
\hline Candida albicans ATCC 20231 & $92 \pm 0.07$ & $89 \pm 0.07$ & $81 \pm 0.07$ & $71 \pm 0.13$ & $68 \pm 0.07$ & $47 \pm 0.20$ & $45 \pm 0.20$ & 0 \\
\hline Candida albicans SC5314 & $99 \pm 0.07$ & $98 \pm 0.07$ & $98 \pm 0.07$ & $97 \pm 0.07$ & $96 \pm 0.07$ & $88 \pm 0.07$ & $87 \pm 0.07$ & 0 \\
\hline
\end{tabular}


Table 3 Activity of cell dislodging in the microtiter plate by pseudofactin II.

\begin{tabular}{|c|c|c|c|c|c|c|c|c|}
\hline \multirow[t]{3}{*}{ Microorganism } & \multicolumn{8}{|c|}{ Microbial adhesion dislodging (\%) } \\
\hline & \multicolumn{7}{|c|}{ Pseudofactin II concentration (mg/ml) } & \multirow{2}{*}{$\begin{array}{l}\text { Control (PBS) } \\
0\end{array}$} \\
\hline & 0.500 & 0.35 & 0.250 & 0.200 & 0.150 & 0.075 & 0.035 & \\
\hline Escherichia coli ATCC 25922 & $66 \pm 0.07$ & $62 \pm 0.07$ & $62 \pm 0.13$ & $55 \pm 0.07$ & $42 \pm 0.20$ & $7 \pm 0.07$ & $4 \pm 0.07$ & 0 \\
\hline Escherichia coli ATCC 10536 & $64 \pm 0.07$ & $62 \pm 0.13$ & $61 \pm 0.13$ & $58 \pm 0.07$ & $50 \pm 0.07$ & $41 \pm 0.07$ & $38 \pm 0.13$ & 0 \\
\hline Escherichia coli 17-2 & $70 \pm 0.13$ & $65 \pm 0.13$ & $59 \pm 0.13$ & $51 \pm 0.07$ & $46 \pm 0.13$ & $27 \pm 0.07$ & $18 \pm 0.07$ & 0 \\
\hline Enterococcus faecalis ATCC 29212 & $48 \pm 0.07$ & $42 \pm 0.13$ & $35 \pm 0.13$ & $33 \pm 0.13$ & $23 \pm 0.13$ & $20 \pm 0.13$ & $10 \pm 0.07$ & 0 \\
\hline Enterococcus faecalis $\mathrm{JA} / 3$ & $26 \pm 0.26$ & $23 \pm 0.26$ & $16 \pm 0.26$ & $15 \pm 0.13$ & $10 \pm 0.07$ & $6 \pm 0.07$ & $4 \pm 0.20$ & 0 \\
\hline Enterococcus hirae ATCC 10541 & $45 \pm 0.13$ & $43 \pm 0.13$ & $41 \pm 0.33$ & $35 \pm 0.20$ & $32 \pm 0.20$ & $31 \pm 0.07$ & $25 \pm 0.13$ & 0 \\
\hline Staphylococcus epidermidis KCTC 1917 & $43 \pm 0.07$ & $39 \pm 0.26$ & $37 \pm 0.07$ & $36 \pm 0.07$ & $23 \pm 0.13$ & $20 \pm 0.13$ & $17 \pm 0.26$ & 0 \\
\hline Proteus mirabilis ATCC 21100 & $45 \pm 0.26$ & $42 \pm 0.26$ & $40 \pm 0.13$ & $34 \pm 0.13$ & $28 \pm 0.07$ & $24 \pm 0.07$ & $21 \pm 0.07$ & 0 \\
\hline Candida albicans ATCC 20231 & $29 \pm 0.26$ & $22 \pm 0.07$ & $21 \pm 0.07$ & $16 \pm 0.07$ & $11 \pm 0.07$ & $6 \pm 0.07$ & $3 \pm 0.07$ & 0 \\
\hline Candida albicans SC5314 & $39 \pm 0.07$ & $31 \pm 0.07$ & $24 \pm 0.13$ & $20 \pm 0.13$ & $17 \pm 0.07$ & $7 \pm 0.13$ & $6 \pm 0.13$ & 0 \\
\hline
\end{tabular}

Negative controls (PBS) were set at $0 \%$. Values \pm confidence interval, $n=9$

$\mathrm{mg} / \mathrm{ml}$ on polystyrene, glass and silicone surfaces (Figures 1E-H, 1M-P and 1W-Z). E. faecalis ATCC 29212 adhesion to all tested surfaces is less intensive than others strains (Figures 1B, J, S). In fact, the adhesion of this strain to 96 wells plate was between 2 to 4 -fold weaker than others tested bacterial strains (data not shown). This effect may be due to small amount of adhesion proteins on E. faecalis ATCC 29212 strain. Pseudofactin in the tested concentration inhibited mixed biofilm formation (data not shown), similarly as for the single strain (Figure 1). In our experiments all the tested Gram-negative and Gram-positive bacteria showed decrease of adhesion. The results of the present study indicate that pseudofactin II have potential to be used for efficient removal and inhibition of biofilms for pathogenic microorganisms.

Rivardo et al. [9] demonstrated that biosurfactants obtained from Bacillus spp. were able to inhibit biofilm formation for two pathogenic strains E. coli at $97 \%$ and $S$. aureus at $90 \%$, respectively. Irie et al. [31] demonstrated that rhamnolipids produced by $P$. aeruginos $a$ were able to disperse biofilm for Bordetella bronchiseptica.

\section{Pseudofactin II prevents biofilm formation in urethral catheters}

To test biofilm formation on medical device, silicone urethral catheters, $4 \mathrm{~cm}$ segments of the catheters were incubated with E. coli ATCC 25922, E. faecalis ATCC 29212, E. hirae ATCC 10541 and C. albicans SC 5314. E. coli, E. faecalis and E. hirae formed biofilms mainly at the air-liquid interface, while the biofilm formed by C. albicans was dispersed along the whole growth surface (Figure 2). Even though the pseudofactin II present in the growth medium (Figure 2A), was at the concentration of $0.25 \mathrm{mg} / \mathrm{ml}$ which did not significantly affect the growth of the tested microbial cultures, biofilm formation was nearly completely prevented. The pretreatment of silicone urethral catheters with pseudofactin II prior to inoculation with medium was just as effective as including the biosurfactant in the growth medium (Figure 2B). We observed the similar effect in dynamic conditions for urethral catheters using a flow of $50 \mathrm{ml} / \mathrm{h}$ (data not shown).

Earlier reports noted an inhibition of biofilms formed by several microorganisms, e.g. Salmonella typhimurium, S. enterica, E. coli and P. mirabilis on vinyl urethral catheters by a surfactin produced by B. subtilis [32].

Our results show that pseudofactin II is promising compound for inhibition and disruption of biofilms and has potential applications in medicine.

\section{Conclusions}

The biosurfactant pseudofactin II, produced by $P$. fluorescens BD5 strain and purified by HPLC, showed antiadhesive activity against several pathogenic microorganisms, such as E. coli, E. faecalis, E. hirae, S. epidermidis, P. mirabilis and C. albicans, which are potential biofilm formers on catheters, implants and internal prostheses. Up to $99 \%$ prevention of $C$. albicans SC 5314 adhesion could be achieved by $0.5 \mathrm{mg} / \mathrm{ml}$ pseudofactin II. Confocal laser scanning microscopy confirmed the action of pseudofactin II as an inhibitor of biofilm formation. In addition, pseudofactin II dispersed preformed biofilms. Due to its surface tension properties and lack of hemolytic activity (data not shown), pseudofactin II can be used as a surface coating agent against microbial colonization of different surfaces, e.g. implants or urethral catheters.

\section{Acknowledgements}

This work was financial supported by grants from the Polish National Centre for Science N N302 640940, Polish National Centre for Research and Development KB/48/13639/IT1-B/U/08 and grant EU POIG.01.01.02-00-016/2008. 


\section{Author details}

${ }^{1}$ Faculty of Biotechnology, University of Wroclaw, Przybyszewskiego 63/77, Wroclaw 51-148, Poland. ${ }^{2}$ Faculty of Chemistry, Wroclaw University of Technology, Gdańska 9/7, Wroclaw 50-344, Poland.

\section{Authors' contributions}

TJ carried out experiments, ML participated in the design of the study, data analysis, coordination and helped to draft the manuscript, AK conceived the experiments and draft the manuscript. All authors read and approved the final manuscript.

Received: 16 September 2011 Accepted: 23 February 2012 Published: 23 February 2012

\section{References}

1. Nikolaev I, Plakunov VK: Biofilm-"City of microbes" or an analogue of multicellular organisms? Microbiologia 2007, 76:149-163.

2. Vediyappan G, Rossignol T: d'Enfert C: Interaction of Candida albicans biofilms with antifungals: transcriptional response and binding of antifungals to beta-glucans. Antimicrob Agents Chemother 2010, 54:2096-2111.

3. Zhao T, Liu Y: N-acetylcysteine inhibit biofilms produced by Pseudomonas aeruginosa. BMC Microbiology 2010, 10:140.

4. Das $P$, Mukherjee $S$, Sen R: Antiadhesive action of a marine microbial surfactant. Colloids and Surfaces B: Biointerfaces 2009, 71:183-186.

5. Rosenberg E, Ron EZ: High- and low-molecular-mass microbia surfactants. Appl Microbiol Biotechnol 1999, 52:154-162.

6. Mukherjee S, Das P, Sen R: Towards commercial production of microbial surfactants. Trends Biotechnol 2006, 24:509-515.

7. Sotirova AV, Spasova DI, Galabova DN, Karpenko E, Shulga A: Rhamnolipidbiosurfactant permeabilizing effects on Gram-positive and Gramnegative bacterial strains. Curr Microbiol 2008, 56:639-644.

8. Dusane DH, Nancharaiah YV, Zinjarde SS, Venugopalan VP: Rhamnolipid mediated disruption of marine Bacillus pumilus biofilms. Colloids and Surfaces B: Biointerfaces 2010, 81:242-248.

9. Rivardo F, Turner RJ, Allegrone G, Ceri H, Martinotti MG: Anti-adhesion activity of two biosurfactants produced by Bacillus spp. prevents biofilm formation of human bacterial pathogens. Appl Microbiol Biotechnol 2009, 83:541-553.

10. Huang X, Lu Z, Zhao H, Bie X, Lü FX, Yang S: Antiviral activity of antimicrobial lipopeptide from Bacillus subtilis fmbj against pseudorabies virus, porcine parvovirus, newcastle disease virus and infectious bursal disease virus in vitro. Int J Pept Res Ther 2006, 12:373-377.

11. Rodrigues L, Banat IM, Teixeira J, Oliveira R: Biosurfactants: potential applications in medicine. J Antimicrob Chemother 2006, 57:609-618.

12. Vollenbroich D, Pauli G, Ozel M, Vater J: Antimycoplasma properties and application in cell culture of surfactin, a lipopeptide antibiotic from Bacillus subtilis. Appl Environ Microbiol 1997, 63:44-49.

13. Banat IM, Makkar RS, Cameotra SS: Potential commercial applications of microbial surfactants. Appl Microbiol Biotechnol 2000, 53:495-508.

14. Singh P, Cameotra SS: Potential applications of microbial surfactants in biomedical sciences. Trends Biotechnol 2004, 22:142-146.

15. Velraeds MMC, van der Mei HC, Reid G, Busscher HJ: Inhibition of initial adhesion of uropathogenic Enterococcus faecalis by biosurfactants from Lactobacillus isolates. Appl Environ Microbiol 1996, 62:1958-1963.

16. Busscher HJ, van der Kuij-Booij M, van der Mei HC: Biosurfactants from thermophilic dairy streptococci and their potential role in the fouling control of heat exchanger plates. J Ind Microbiol Biotechnol 1996, 16:15-21.

17. Krasowska A, Łukaszewicz M: Isolation, identification of Arctic microorganisms, and their proteolytic and lipolytic activity (Izolacja, identyfikacja oraz aktywność proteolityczna i lipolityczna mikroorganizmów arktycznych). Acta Sci Pol Biotech 2011, 10:3-12 [http:// www.aqua.ar.wroc.pl/acta/pl/full/3/2011/000030201100010000010000500014. pdf].

18. Krasowska A, Dąbrowska B, Łukaszewicz M: Isolation and characterization of microorganisms from Arctic archipelago of Svalbard. J Biotechnol 2007, 131:S240.

19. Janek T, Łukaszewicz M, Rezanka T, Krasowska A: Isolation and characterization of two new lipopeptide biosurfactants produced by Pseudomonas fluorescens BD5 isolated from water from the Arctic Archipelago of Svalbard. Bioresource Technol 2010, 101:6118-6123.
20. Kim KM, Lee JY, Kim CK, Kang JS: Isolation and characterization of surfactin produced by Bacillus polyfermenticus KJS-2. Arch Pharm Res 2009, 32:711-715.

21. Gillum AM, Tsay EY, Kirsch DR: Isolation of the Candida albicans gene for orotidine-50-phosphate decarboxylase by complementation of $S$. cerevisiae ura3 and E. coli pyrF mutations. Mol Gen Genet 1984, 198:179-182.

22. Laycock M, Hildebrand PD, Thibault P, Walter JA, Wright JLC: Viscosin, a potent peptidolipid biosurfactant and phytopathogenic mediator produced by a pectolytic strain of Pseudomonas fluorescens. J Agr Food Chem 1991, 39:483-489.

23. Youssef $\mathrm{NH}$, Duncan KE, Mclnerney MJ: Importance of 3-hydroxy fatty acid composition of lipopeptides for biosurfactant activity. App/ Environ Microbiol 2005, 71:7690-7695.

24. Peng F, Wang Y, Sun F, Liu Z, Lai Q, Shao Z: A novel lipopepitide produced by a Pacific Ocean deep-sea bacterium, Rhodococcus sp. TW53. J Appl Microbiol 2008, 105:698-705.

25. Peypoux F, Bonmatin JM, Wallach J: Recent trends in the biochemistry of surfactin. Appl Microbiol Biotechnol 1999, 51:553-563.

26. Besson F, Peypoux F, Michel G, Delcambe L: Characterization of iturin A in antibiotics from various strains of Bacillus subtilis. J Antibiot 1976, 29:1043-1049.

27. Grangemard I, Wallach J, Maget-Dana R, Peypoux F: Lichenysin: a more efficient cation chelator than surfactin. Appl Biochem Biotechnol 2001, 90:199-210.

28. Landman D, Georgescu C, Martin DA, Quale J: Polymyxins revisited. Clin Microbiol Rev 2008, 21:449-465.

29. De Araujo LV, Abreu F, Lins U, de Melo Santa Anna LM, Nitschke M, D Guimarăes Freire DM: Rhamnolipid and surfactin inhibit Listeria monocytogenes adhesion. Food Research International 2011, 44:481-488.

30. Gudińa EJ, Teixeira JA, Rodrigues LR: Isolation and functional characterization of a biosurfactant produced by Lactobacillus paracasei. Colloids Surf B 2010, 76:298-304

31. Irie Y, OToole GA, Yuk MH: Pseudomonas aeruginosa rhamnolipids disperse Bordetella bronchiseptica biofilms. FEMS Microbiology Lett 2005, 250:237-243.

32. Mireles JR, Toguchi A, Harshey RM: Salmonella enterica serovar Typhimurium swarming mutants with altered biofilm-forming abilities: surfactin inhibits biofilm formation. J Bacteriol 2001, 183:5848-5854.

doi:10.1186/1471-2180-12-24

Cite this article as: Janek et al:: Antiadhesive activity of the biosurfactant pseudofactin II secreted by the Arctic bacterium Pseudomonas fluorescens BD5. BMC Microbiology 2012 12:24.

\section{Submit your next manuscript to BioMed Central and take full advantage of:}

- Convenient online submission

- Thorough peer review

- No space constraints or color figure charges

- Immediate publication on acceptance

- Inclusion in PubMed, CAS, Scopus and Google Scholar

- Research which is freely available for redistribution 